\title{
Cardiovascular Risk Factors and Risk Measurement in Patients with Psoriatic Arthritis in a University Hospital
}

\author{
Beatriz Pinto e Siqueira Campos, ${ }^{\circledR}$ Gustavo Daniel dos Santos Gomes, ${ }^{\circledR}$ Alessandra de Sousa Braz, ${ }^{\circledR}$ Andre Telis \\ de Vilela ${ }^{\circledR}$ \\ Universidade Federal da Paraíba - Centro de Ciências Médicas (CCM), João Pessoa, PB - Brazil
}

\section{Abstract}

Background: Psoriatic Arthritis is the spondyloarthritis associated with psoriasis, which is often related to high mortality due to cardiovascular causes.

Objectives: To quantify cardiovascular risk factors (hypertension, diabetes, dyslipidemia, obesity and smoking) and to measure risk by the Global Cardiovascular Risk Score in patients with psoriatic arthritis.

Methods: Patients with psoriatic arthritis according to the Classification Criteria for Psoriatic Arthritis, aged between 30 and 74 years and without any other clinically manifest chronic inflammatory disease, atherosclerotic disease or heart failure were included. After an interview, clinical examination and data extraction from medical records, risk stratification was performed using a calculator available on the online platform of the Framingham Heart Study. We considered $\mathrm{p}<0.05$ as significant. Chi-square test and Fisher's exact test were used to compare frequencies, as well as correlation measurements.

Results: 45 patients were included, 68,9\% of which were women and the mean age was 53,94 years. Dyslipidemia was confirmed in approximately $93 \%$, hypertension in $46 \%$, obesity in $40 \%, 33.3 \%$ were diabetics and, $13.3 \%$, smokers; 95\% had increased abdominal circumference. It was observed that 53\% had high cardiovascular risk, $29 \%$ had intermediate risk and $18 \%$ had low risk. Individuals with altered C-reactive protein and erythrocyte sedimentation rate presented, respectively, higher levels of LDL-C and total cholesterol.

Conclusions: There was a high occurrence of risk factors and the majority of the sample was stratified into high or intermediate cardiovascular risk. (Int J Cardiovasc Sci. 2020; 33(2):112-118)

Keywords: Cardiovascular Diseases; Risk Factors; Obesity; Dyslipidemias; Inflammation; Arthritis, Psoriatic.

\section{Introduction}

Psoriasis is a chronic immune-mediated inflammatory disease, which classically involves the skin and affects $1.3 \%$ of the Brazilian population. ${ }^{1-3}$ Psoriatic arthritis (PsA) is an inflammatory joint pathology that occurs in association with psoriasis, present in 10 to $30 \%$ of those with cutaneous manifestations. ${ }^{4,5}$ The course of PsA ranges from mild manifestations to a debilitating picture. Skin injuries usually precede arthropathy and severity of cutaneous disease is unrelated to joint disease activity. ${ }^{6}$ Its pathogenesis is not well established, but genetic, immunological, environmental factors infections and traumas - obesity and smoking are likely to be involved. ${ }^{7-14}$

The CASPAR (Classification Criteria for Psoriatic Arthritis) criteria are those recommended by the Brazilian Society of Rheumatology for PsA classification and diagnosis. It takes into account the presence of inflammatory joint disease associated with some of the following: current psoriasis, personal or family history of psoriasis, dactylitis, juxta-articular bone formation (in hands or feet), negative rheumatoid factor and psoriasis 
onychodystrophy. Sensitivity and specificity of this method are $99.7 \%$ and $99.1 \%$, respectively. ${ }^{15}$

Inflammatory rheumatologic diseases are associated with high mortality, largely due to cardiovascular causes. It may be justified by an increase in inflammatory cytokines, atherosclerosis, endothelial dysfunction, individual genetics, use of medications with a negative effect on the cardiovascular system, in addition to traditional risk factors. ${ }^{16}$ Psoriasis is related to increased risk of acute myocardial infarction (AMI), especially in severe cases. ${ }^{17-20}$

However, unlike other inflammatory diseases, these patients are more often obese. The pathophysiology of psoriasis and obesity involves many common cytokines that contribute to the components of metabolic syndrome: hypertension, dyslipidemia and insulin resistance. ${ }^{14,18}$ In addition to the presence of comorbidities that act as a cardiovascular risk (CVR) factor, many studies detected increased rates of cardiovascular disease in this group. ${ }^{19,21,22}$ Only one in every seven patients with psoriasis is aware of the atherosclerotic disease and metabolic syndrome risk they present. ${ }^{23}$ Characterization of an association between PsA and increased CVR would justify automatic reclassification of patients with this condition in high CVR, without the need for scores that could attribute different risk.

\section{Objectives}

To quantify cardiovascular risk factors (hypertension, diabetes, dyslipidemia, obesity and smoking) and to measure risk by the Global Cardiovascular Risk Score in patients with psoriatic arthritis.

\section{Methods}

Cross-sectional study carried out between September 2016 and June 2017 at the Rheumatology outpatient clinic of Hospital Universitário Lauro Wanderley (HULW), João Pessoa - PB.

\section{Population and sample}

Study population consisted of all PsA patients followed at the rheumatology outpatient clinic of a reference hospital. Sample was chosen for convenience and a non-probabilistic stratified sample was adopted, due to the low prevalence of the disease.

\section{Inclusion criteria}

The study included patients classified according to the CASPAR criteria ${ }^{24}$ (evaluated by a rheumatologist); aged between 30 and 74 years, since the Global Cardiovascular Risk Score (GCRS) used is restricted to individuals of this age group. ${ }^{25}$ After adequate information, the patients signed the informed consent form (ICF).

\section{Exclusion criteria}

Patients with clinically manifest heart failure or atherosclerotic cardiovascular disease (coronary, cerebrovascular or peripheral occlusive disease) were excluded, until assessment, since the score used estimates the risk of onset and does not apply to patients with manifested cardiovascular disease. ${ }^{25}$ Individuals diagnosed with another chronic inflammatory disease, other than PsA, were also eliminated.

\section{Instruments for data collection}

The CASPAR ${ }^{24}$ criteria were used to confirm PsA classification/diagnosis; sociodemographic and clinical questionnaire based on the Framingham score ${ }^{25}$ was used for global CVR; and a specific calculator was used for risk assessment, available on the online platform of the Framingham Heart Study; in addition to medical records data.

\section{Procedures for data collection}

This study was approved by the Research Ethics Committee of HULW - João Pessoa, PB - under protocol number 56336216.1.0000.5183.

Psoriatic arthritis patients underwent an interview and clinical examination for data collection and risk stratification according to the Framingham score ${ }^{25}$ for global CVR. The most recent data of laboratory results were used with a maximum delay of six months between testing and evaluation.

This score considers the following: age, High Density Lipoprotein Cholesterol (HDL-C), total cholesterol, untreated systolic blood pressure (SBP) or treated SBP, smoking and diabetes. Age, condition of hypertension, smoking and diabetes are self-reported by the research participant, while HDL-C, total cholesterol, triglycerides, C-reactive protein (CRP) and erythrocyte sedimentation rate (ESR) were obtained from the medical record. 
The SBP used to calculate the CVR was measured by the researchers during the interview, as well as height and weight - for calculation of body mass index (BMI) - and abdominal circumference.

This score quantifies the percentage risk of developing the main cardiovascular events - coronary artery disease (CAD), stroke, peripheral arterial disease or heart failure - in the next 10 years. Patients with less than $5 \%$ probability of presenting any of the aforementioned outcomes were considered at low risk. Patients at intermediate risk were males with calculated risk between $5 \%$ and $20 \%$ or females with risk between $5 \%$ and $10 \%$. High-risk individuals were men with calculated risk greater than $20 \%$ and women whose risk is greater than $10 \%{ }^{26}$

\section{Data analysis}

The sociodemographic and clinical characteristics were analyzed through descriptive statistics using frequencies for categorical variables, and mean and standard deviation (SD) for parametric scalar variables with a $95 \%$ confidence interval $(95 \% \mathrm{CI})$, or median and interquartile range (IQR) for non-parametric variables. Shapiro-Wilk test was used to evaluate normality.

In inferential analysis, Chi-square and Fisher's exact test were used to compare frequencies between independent groups. To evaluate the correlation between two scalar variables, the Spearman method was used. Mann-Whitney test was used for independent samples. We considered $\mathrm{p}<0.05$ as significant. Statistical analysis was performed using the SPSS for MAC program (23.0 version).

\section{Results}

Among the 45 study participants, most were female $(68.90 \%)$ and the mean age was 53.94 years (standard deviation 9.8). The sociodemographic data are shown in Table 1. The distribution of cutaneous psoriasis and AP forms is shown in Table 2.

Most of the sample had plaque psoriasis alone (32 individuals) and the most prevalent type of arthritis in this study was symmetrical polyarthritis (41 individuals), of which five also presented spondylitis. Most of the patients were diagnosed with cutaneous psoriasis prior to the diagnosis of PsA (66.67\%), 24.44\% had both diagnoses on the same occasion, and $8.89 \%$ had PsA before cutaneous manifestations. There was no difference in the types of psoriasis or the time of diagnosis of psoriasis or PsA between the different groups of CVR.

Regarding the frequency of CVR factors among the patients in this study, dyslipidemia was present in $93 \%$ of the sample, $46 \%$ were hypertensive, $40 \%$ were obese (BMI $\geq 30 \mathrm{~kg} / \mathrm{m}^{2}$ ), 33.3\% had type 2 diabetes mellitus, $13.3 \%$ self-reported smoking, and 95\% presented increased abdominal circumference.

Among the 45 participants, 43 had increased waist circumference, that is, women with a circumference greater than or equal to $80 \mathrm{~cm}$ and men with an abdominal

Table 1 - Socio-demographic data

\begin{tabular}{lcc}
\hline Variables & $\mathbf{N}$ & $\%$ \\
\hline Sex & 31 & \\
Female & 14 & 68.89 \\
Male & & 31.11 \\
Ethnicity & 08 & \\
White & 37 & 17.78 \\
Non-white & & 82.22 \\
\hline
\end{tabular}

Table 2 - Absolute frequency and percentage of each type of psoriasis and PsA

\begin{tabular}{lcc}
\hline Variables & N & $\%$ \\
\hline Type of psoriasis & 32 & 71.11 \\
$\quad$ Plaque & 07 & 15.56 \\
$\quad$ Palmoplantar & 03 & 6.67 \\
$\quad$ Plaque + Palmoplantar & 02 & 4.44 \\
Guttate & 01 & 2.22 \\
Generalized Pustular & & \\
Arthritis type & 36 & 80.00 \\
Symmetrical polyarthritis & 05 & 11.12 \\
Symmetric polyarthritis + \\
spondylitis
\end{tabular}


waist greater than or equal to $90 \mathrm{~cm} \cdot{ }^{27}$ Patients who presented at least one of the following were considered dyslipidemic: LDL-C > $130 \mathrm{mg} / \mathrm{dL}$ or triglycerides $>150$ $\mathrm{mg} / \mathrm{dl}$, values adopted by the 2017 Brazilian Dyslipidemia and Atherosclerosis Prevention Guideline. ${ }^{26}$

Individuals with altered serum CRP and ESR levels presented, respectively, higher levels of LDL-C $(p=0.02)$ and total cholesterol $(p=0.04)$. There was no significant difference between serum levels of CRP or ESR according to the different categories of CVR - low, intermediate or high risk.

Participants in this study had a median CVR of $13.70 \%$ (IQR 5.6-25.3). Patients at high risk for cardiovascular outcomes in the next 10 years accounted for $53 \%$ of the sample, $29 \%$ had intermediate risk and $18 \%$ were low risk.

Psoriatic arthritis medications used by the participants in this research data collection period are listed in Table 3. No association was found between the medication used and the calculated CVR compared by Fisher's exact test. Analyzing the presence of CVR factors and the type of medication used, it was evidenced that patients using leflunomide had significantly higher BMI $(\mathrm{t}=2.41, \mathrm{p}=0.03)$

\section{Discussion}

This study was performed to quantify risk factors and to assess the CVR of PsA patients followed at a tertiary referral hospital in northeastern Brazil. Corroborating with the high CVR found in the sample, in 2013, a systematic review evidenced increased risk of AMI, cardiovascular

\begin{tabular}{lcc}
$\begin{array}{l}\text { Table } 3 \text { - Absolute frequency and percentage of each } \\
\text { type of medication used for PsA }\end{array}$ & N & $\%$ \\
\hline Medication & 26 & 57.78 \\
\hline Metotrexate & 10 & 22.22 \\
Leflunomide & 08 & 17.78 \\
Adalimumab & 07 & 15.56 \\
Infliximab & 03 & 6.67 \\
Corticoid & 02 & 4.44 \\
Ustekinumab & 02 & 4.44 \\
Etanercept & 01 & 2.22 \\
Naproxen & 04 & 8.89 \\
\hline None & &
\end{tabular}

mortality and stroke in patients with aggressive psoriasis - those who, by definition, require hospital admission or systemic therapy which includes carriers of PsA. Other manifestations of atherosclerotic disease also have increased frequency in patients with psoriasis, such as stroke and peripheral arterial disease. ${ }^{27}$ Although notorious, the high occurrence of CVR factors, as well as the risk estimated by GCRS ${ }^{25}$ in patients with PsA, do not provide enough evidence to use a multiplier factor for the usual scores, as in rheumatoid arthritis, for example, in which the calculated risk is multiplied by $1.5 .^{28}$

Prevalence of hypertension, obesity, hyperlipidemia, type 2 diabetes and the occurrence of at least one cardiovascular event were $37.1 \%, 30 \%, 20.7 \%, 12 \%$ and $8.2 \%$, respectively, resulting in a $4.9 \%$ increase in the risk of cardiovascular disease, $17.5 \%$ in hypertension, $6.2 \%$ in hyperlipidemia, $5.3 \%$ in type 2 diabetes and $3.5 \%$ in obesity compared with patients with psoriasis without arthritis..$^{29}$ A 2013 systematic review found a higher prevalence of hypertension in psoriasis patients than in the control group. ${ }^{30}$ The same occurred with diabetes in another systematic review of the same year. ${ }^{31}$ A population study from the UK found an increased smoking frequency, and all previously mentioned risk factors in psoriasis patients compared to the control group. ${ }^{32}$ The sample of this study also revealed a high occurrence of the main predictors of CVR, especially dyslipidemia. The prevalence of hyperlipidemia found in the Canadian study is considerably lower, which may be justified by the non-contribution of low HDL-C patients in the Canadian research statistics, in addition to the current cut-off points being more stringent.

Similar to this study, in which the majority of individuals was diagnosed with psoriasis before articular manifestations, skin disease precedes arthritis in approximately $75 \%$ of the cases, is simultaneous in $10 \%$ of the diagnoses and occurs afterwards in $15 \%{ }^{33}$

Studies reveal a large range of variation in the incidence of each type of joint involvement: $15 \%-78 \%$ of the polyarticular form, $16 \%-70 \%$ of asymmetric oligoarthritis, $1 \%-17 \%$ of the form affecting the distal interphalangeal, $2 \%-16 \%$ of the mutilating form and $2 \%-27 \%$ of spondylitis. The overlap between the several subgroups of PsA is frequent and the joint involvement can change, so that patients starting symptomatology with asymmetric oligoarthritis can develop symmetrical polyarthritis over time, for example. Thus, the current trend is to classify PsA in three main clinical presentations: polyarticular, oligoarticular and axial; it is estimated that 
they correspond to $41 \%, 31 \%$ and $28 \%$ of the patients, respectively. ${ }^{33}$ In this study, the polyarticular form was also the most prevalent, followed by the overlap of this form with spondylitis.

A 2009 retrospective cohort study using a UK database, estimated to represent $5 \%$ of the population in this region, found an increased risk of stroke in PsA, which was higher according to the severity of the disease. ${ }^{34}$ The presence of high levels of inflammatory biomarkers -- suggestive of increased disease activity - were predictors of clinical cardiovascular events in the study by Husted J.A. et al. ${ }^{29}$ In our study, individuals with serum alterations of CRP and ESR presented, respectively, higher levels of LDL-C and total cholesterol, factors known to be related to the development of atherosclerosis and its consequences. However, there was no significant difference between serum levels of CRP or ESR according to the different categories of CVR - low, intermediate or high risk.

Psoriatic arthritis drug therapy includes non-steroidal anti-inflammatory drugs (NSAIDs), glucocorticoids and disease-modifying drugs (DMDs) - sulfasalazine, methotrexate, leflunomide and biological agents. DMDs are defined as drugs capable of preventing disease progression. ${ }^{35}$ NSAIDs and glucocorticoids, used to alleviate PsA symptoms, are associated with an increase in unfavorable cardiovascular outcomes, such as AMI, which, in a way, may also eventually contribute to the increase of CVR. ${ }^{36,37}$ On the other hand, in several studies, DMDs are related to reduced CVR. Risk was reduced in patients using these medications compared to those who used other systemic therapies, probably because of the greater effectiveness in reducing the disease activity, reducing inflammation and its propensity to the formation of atherosclerosis. Inflammation suppression by immunomodulatory agents represents a promising new target for the management of cardiovascular diseases both in the general population and among patients with chronic inflammatory conditions. ${ }^{27,38}$ Methotrexate is the first-line DMD in PsA, due to its effectiveness in the treatment of cutaneous and joint involvement combined with its low cost. Its anti-inflammatory effect is mediated by adenosine and can neutralize neutrophils, T-cells and macrophages - the main agents in the pathogenesis of psoriasis and PsA. ${ }^{33,39}$ Currently, the most widely used biological DMDs for PsA treatment, and approved by the Brazilian National Agency of Sanitary Surveillance (ANVISA), are the TNF- $\alpha$ inhibitors: etanercept, adalimumab, golimumab, infliximab, and certolizumab pegol. ${ }^{40}$ However, in this study, there was no significant difference in cardiovascular parameters according to the different medications in use.

This research presented some limitations, because, although performed in a specialized outpatient clinic, the sample obtained was small and there was no comparison with the control group, thus no inferences could be made. Since it was an observational study, it was subject to memory bias. In addition, it was hampered by the lack of data in the medical records.

\section{Conclusions}

Most of the patients in the sample were stratified as high or intermediate CVR. Despite the high incidence of CVR factors, there was no parallel between them and the time of PsA diagnosis. It is recommended to use traditional CVR scores since there is not enough evidence to use a multiplier factor in this estimation, or to use a different calculator.

\section{Authors' contributions}

Research creation and design: Campos B, Gomes G, Telis A. Data acquisition: Campos B. Data analysis and interpretation: Campos B, Telis A. Statistical analysis: Telis A. Writing: Campos B, Gomes G, Braz A, Telis A. Critical revision of the manuscript for intellectual content: Braz A, Telis A. Supervision/major investigator: Telis A.

\section{Potential Conflict of Interest}

No potential conflict of interest relevant to this article was reported.

\section{Sources of Funding}

There were no external funding sources for this study.

\section{Study Association}

This study is not associated with any thesis or dissertation work.

\section{Ethics approval and consent to participate}

This study was approved by the Ethics Committee of Universidade Federal da Paraíba under protocol number CAAE: 56336216.1.0000.5183. All the procedures in this study were in accordance with the 1975 Helsinki Declaration, updated in 2013. Informed consent was obtained from all participants included in the study. 


\section{References}

1. Gelfand JM, Weinstein R, Porter SB, Neimann AL, Berlin JA, Margolis DJ. Prevalence and treatment of psoriasis in the United Kingdom: a population-based study. Arch Dermatol. 2005;141(12):1537-41.

2. Sociedade Brasileira de Dermatologia. Consenso Brasileiro de Psoríase 2012 - Guias de avaliação e tratamento. 2a ed. Rio de Janeiro; 2012.

3. World Health Organization.(WHO). Global report on psoriasis.2016. [ Cited in $201823 \mathrm{dez}$ ] [ Available in: http://www.who.int/iris/ handle/10665/204417]

4. Mease PJ, Gladman DD, Papp KA, Khraishi MM, Thaci D, Behrens F, et al. Prevalence of rheumatologist-diagnosed psoriatic arthritis in patients with psoriasis in European/North American dermatology clinics. J Am Acad Dermatol. 2013;69(5):729-35.

5. Farley E, Menter A. Psoriasis: comorbidities and associations. G Ital Dermatol Venereol. 2011;146(1):9-15.

6. Gottlieb AB, Kircik L, Eisen D, Jackson JM, Boh EE, Strober BE, et al. Use of etanercept for psoriatic arthritis in the dermatology clinic: the Experience Diagnosing, Understanding Care, and Treatment with Etanercept (EDUCATE) study. J Dermatolog Treat. 2006;17(6):343-52.

7. Ritchlin CT. Pathogenesis of psoriatic arthritis. Curr Opin Rheumatol. 2005;17(4):406-12.

8. Prinz JC. Psoriasis vulgaris--a sterile antibacterial skin reaction mediated by cross-reactive T cells? An immunological view of the pathophysiology of psoriasis. Clin Exp Dermatol. 2001;26(4):326-32.

9. Pattison E, Harrison BJ, Griffiths CE, Silman AJ, Bruce IN. Environmental risk factors for the development of psoriatic arthritis: results from a casecontrol study. Ann Rheum Dis. 2008;67(5):672-6.

10. Ko HC, Jwa SW, Song M, Kim MB, Kwon KS. Clinical course of guttate psoriasis: long-term follow-up study. J Dermatol. 2010;37(10):894-9.

11. Armstrong AW, Harskamp CT, Dhillon JS, Armstrong EJ. Psoriasis and smoking: a systematic review and meta-analysis. Br J Dermatol. 2014;170(2):304-14.

12. Bremmer S, Van Voorhees AS, Hsu S, Korman NJ, Lebwohl MG, Young M, et al. Obesity and psoriasis: from the Medical Board of the National Psoriasis Foundation. J Am Acad Dermatol. 2010;63(6):1058-69.

13. Cullen G, Kroshinsky D, Cheifetz AS, Korzenik JR. Psoriasis associated with anti-tumour necrosis factor therapy in inflammatory bowel disease: a new series and a review of 120 cases from the literature. Aliment Pharmacol Ther. 2011;34(11-12):1318-27.

14. Vlam K, Gottlieb AB, Mease PJ. Current concepts in psoriatic arthritis: pathogenesis and management. Acta Derm Venereol. 2014;94(6):627-34.

15. Carneiro S, Azevedo VF, Bonfiglioli R, Ranza R, Goncalves CR, Keiserman $\mathrm{M}$, et al. Recommendations for the management and treatment of psoriatic arthritis. Rev Bras Reumatol. 2013;53(3):227-41.

16. Mota LM, Brenol CV, Pollak DF, Pinheiro GR, Laurindo IM, Pereira IA, et al. Safe use of biological therapies for the treatment of rheumatoid arthritis and spondyloarthritides. Rev Bras Reumatol. 2015; 55(3):281-309.

17. Samarasekera EJ, Neilson JM, Warren RB, Parnham J, Smith CH. Incidence of cardiovascular disease in individuals with psoriasis: a systematic review and meta-analysis. J Invest Dermatol. 2013;133(10):2340-6.

18. Sterry W, Strober BE, Menter A, International Psoriasis C. Obesity in psoriasis: the metabolic, clinical and therapeutic implications. Report of an interdisciplinary conference and review. Br J Dermatol. 2007;157(4):649-55.

19. Horreau C, Pouplard C, Brenaut E, Barnetche T, Misery L, Cribier B, et al. Cardiovascular morbidity and mortality in psoriasis and psoriatic arthritis: a systematic literature review. J Eur Acad Dermatol Venereol. 2013; 27(Suppl 3):12-29.

20. Ogdie A, Yu Y, Haynes K, Love TJ, Maliha S, Jiang Y, et al. Risk of major cardiovascular events in patients with psoriatic arthritis, psoriasis and rheumatoid arthritis: a population-based cohort study. Ann Rheum Dis. 2014; 74(2), 326-32.

21. Samarasekera EJ, Neilson JM, Warren RB, Parnham J, Smith CH. Incidence of cardiovascular disease in individuals with psoriasis: a systematic review and meta-analysis. J Invest Dermatol. 2013;133(10):2340-6.

22. Gelfand JM, Neimann AL, Shin DB, Wang X, Margolis DJ, Troxel AB. Risk of myocardial infarction in patients with psoriasis. JAMA. 2006;296(14):1735-41.

23. Skiveren J, Philipsen P, Therming G. Patients with psoriasis have insufficient knowledge of their risk of atherothrombotic disease and metabolic syndrome. Clin Exp Dermatol. 2015;40(6):600-4.

24. Taylor W, Gladman D, Helliwell P, Marchesoni A, Mease P, Mielants H, et al. Classification criteria for psoriatic arthritis: development of new criteria from a large international study. Arthritis Rheum. 2006;54(8):2665-73.

25. D'Agostino RB, Vasan RS, Pencina MJ, Wolf PA, Cobain M, Massaro JM, et al. General cardiovascular risk profile for use in primary care: the Framingham Heart Study. Circulation. 2008;117(6):743-53.

26. Faludi AA, Izar MC, Saraiva JF, Chacra AP, Bianco HT, Afiune Neto A, et al. Atualização da Diretriz Brasileira de Dislipidemias e Prevenção da Aterosclerose - 2017. Arq Bras Cardiol. 2017;109(2 Suppl 1):1-76.

27. Associação Brasileira para o Estudo da Obesidade e da Síndrome Metabólica. Diretrizes brasileiras de obesidade 4a ed . São Paulo;2016. p.1-186.

28. Agca R, Heslinga SC, Rollefstad S, Heslinga M, McInnes IB, Peters $\mathrm{MJ}$, et al. EULAR recommendations for cardiovascular disease risk management in patients with rheumatoid arthritis and other forms of inflammatory joint disorders: 2015/2016 update. Ann Rheum Dis. 2017;76(1):17-28.

29. Husted JA, Thavaneswaran A, Chandran V, Eder L, Rosen CF, Cook RJ, et al. Cardiovascular and other comorbidities in patients with psoriatic arthritis: a comparison with patients with psoriasis. Arthritis Care Res (Hoboken). 2011;63(12):1729-35.

30. Armstrong AW, Harskamp CT, Armstrong EJ. The association between psoriasis and hypertension: a systematic review and meta-analysis of observational studies. J Hypertens. 2013;31(3):433-42; discussion 42-3.

31. Armstrong AW, Harskamp CT, Armstrong EJ. Psoriasis and the risk of diabetes mellitus: a systematic review and meta-analysis. JAMA Dermatol. 2013;149(1):84-91.

32. Neimann AL, Shin DB, Wang X, Margolis DJ, Troxel AB, Gelfand JM Prevalence of cardiovascular risk factors in patients with psoriasis. J Am Acad Dermatol. 2006;55(5):829-35.

33. Goldenstein-Schainberg C, Favarato MH, Ranza R. Conceitos atuais e relevantes sobre artrite psoriásica. Rev Bras Reumatol. 2012;52(1): 98-106.

34. Gelfand JM, Dommasch ED, Shin DB, Azfar RS, Kurd SK, Wang X, et al. The risk of stroke in patients with psoriasis. J Invest Dermatol. 2009;129(10):2411-8.

35. Ash Z, Gaujoux-Viala C, Gossec L, Hensor EM, FitzGerald O, Winthrop $\mathrm{K}$, et al. A systematic literature review of drug therapies for the treatment of psoriatic arthritis: current evidence and meta-analysis informing the EULAR recommendations for the management of psoriatic arthritis. Ann Rheum Dis. 2012;71(3):319-26.

36. Johnsen SP, Larsson H, Tarone RE, McLaughlin JK, Norgard B, Friis S, et al. Risk of hospitalization for myocardial infarction among users of rofecoxib, celecoxib, and other NSAIDs: a population-based case-control study. Arch Intern Med. 2005;165(9):978-84.

37. Maxwell SR, Moots RJ, Kendall MJ. Corticosteroids: do they damage the cardiovascular system? Postgrad Med J. 1994;70(830):863-70.

38. Eder L, Gladman DD. Atherosclerosis in psoriatic disease: latest evidence and clinical implications. Ther Adv Musculoskelet Dis. 2015;7(5):187-95. 
39. Carneiro S, Azevedo VF, Bonfiglioli R, Ranza R, Gonçalves CR, Keiserman $\mathrm{M}$, et al. Recomendações sobre diagnóstico e tratamento da artrite psoriásica. Rev Bras Reumatol. 2013;53(3):227-41.
40. Acosta Felquer ML, Coates LC, Soriano ER, Ranza R, Espinoza LR, Helliwell PS, et al. Drug therapies for peripheral joint disease in psoriatic arthritis: a systematic review. J Rheumatol. 2014;41(11):2277-85. 